LETTER TO THE EDITOR

\title{
Searching for A3243G mitochondrial DNA mutation in buccal mucosa in order to improve the screening of patients with mitochondrial diabetes
}

\author{
Hervé Narbonne, Danielle Perucca-Lostanlen ${ }^{1}$, Claude Desnuelle ${ }^{1}$, Bernard Vialettes, Anne Saunières ${ }^{1}$ and \\ Véronique Paquis-Flucklinger ${ }^{1}$ \\ Service de Nutrition-Maladies métaboliques-Endocrinologie, Hôpital Sainte Marguerite, Marseille, France and ${ }^{1}$ UMR CNRS/UNSA 6549, \\ Faculté de Médecine, Avenue de Valombrose, 06107 Nice cedex 2, France \\ (Correspondence should be addressed to V Paquis-Flucklinger; Email: paquis@hermes.unice.fr)
}

Since the initial discovery of defects in mitochondrial DNA (mtDNA) as a pathogenic factor for diabetes, many alterations including deletions and point mutations have been described. One of the most common point mutations is an $\mathrm{A}$ to $\mathrm{G}$ mutation at nucleotide 3243 in the tRNA ${ }^{\text {Leu(UUR) }}$ gene. Approximatively $1.5 \%$ of diabetic patients is found to harbor this mutation when mtDNA is extracted from leucocytes. Nevertheless, heteroplasmia hinders the detection of mtDNA point mutations. Pathogenic mutations generally occur in heteroplasmic forms and large variations between various tissues are seen within patients. The amount of mutant mtDNA is higher in muscle than in blood cells, even when diabetic patients have no clinical muscular involvement (1). However, muscle biopsy is an invasive method that cannot be used as a routine examination, especially in diabetic patients. In order to find tissues more informative than blood, we compared the detection rate for pathogenic mtDNA mutations in blood, buccal mucosa and hair follicles.

We studied 10 patients harboring the 3243 mutation and one patient harboring the T14709C tRNA mutation (2). All patients had either a late onset diabetes mellitus or a history of diabetes in maternal relatives. We determined the relative proportions of mutant and wild-type mtDNA in blood, buccal mucosa and hair follicles as previously described (2). For five of the 3243 positive patients, a muscle biopsy was also available. In our study, all patients had a greater level of mutant mtDNA in muscle than in buccal mucosa, hair follicles and blood (Table 1). Patient 5, a 64-year-old man, presented a combination of diabetes, cardiomyopathy, deafness, macular pattern dystrophy, myopathy and chronic diarrhea. This case clearly shows that the percentage of 3243 mutation varies considerably among tissues, with leucocytes being among those having the least heteroplasmy (5\%).

In our study, the most striking point is that the percentage of mutant mtDNA is higher in buccal mucosa than in leucocytes in ten patients. The last one (patient 2) has a similar level of heteroplasmy in these two cell types. Patient 6, a 53-year-old woman, was suspected of having a respiratory chain defect with a suggestive clinical and family history. In leucocytes, neither mtDNA deletion, nor 3243 point mutation were found. A muscle biopsy was performed. Ragged red fibers were present despite the absence of a clinical myopathy, and the 3243 mutation was identified. Both buccal mucosa and hair follicles were examined subsequently and were found to be positive. Muscle biopsy could have been avoided if this test had been carried out first.

In hair follicles, results are more variable, most probably because the percentage of mutated mtDNA is different in various follicles from the same patient (3). The level of heteroplasmy is higher in hair follicles than in blood in 7 patients, lower in 2 cases and similar in 2 patients.

The detection rate of 3243 point mutation is low in blood, mainly in elderly patients because heteroplasmy levels of mutant mtDNA decrease in leucocytes upon aging $(4,5)$. Furthermore, the level of heteroplasmy in blood does not allow the prediction of the age at onset

Table 1 Heteroplasmy levels (\%) in ten patients with the 3243 mutation and one patient with the 14709 mutation.

\begin{tabular}{|c|c|c|c|c|c|c|}
\hline \multirow[b]{2}{*}{$\begin{array}{l}\text { Patient } \\
\text { number }\end{array}$} & \multirow[b]{2}{*}{ Age } & \multirow[b]{2}{*}{ Sex } & \multicolumn{4}{|c|}{$\%$ mutant mtDNA } \\
\hline & & & Blood & $\begin{array}{c}\text { Buccal } \\
\text { mucosa }\end{array}$ & $\begin{array}{l}\text { Hair } \\
\text { follicle }\end{array}$ & Muscle \\
\hline \multicolumn{7}{|c|}{3243 mutant mtDNA } \\
\hline 1 & 59 & $\mathrm{M}$ & 3 & 8 & 3 & 66 \\
\hline 2 & 69 & $\mathrm{~F}$ & 3 & 3 & 6 & 36 \\
\hline 3 & 56 & M & 1.5 & 18 & 14 & 44 \\
\hline 4 & 56 & $\mathrm{~F}$ & 11 & 29 & 20 & 74 \\
\hline $5^{\star}$ & 64 & M & 5 & 15 & 3 & ND \\
\hline 6 & 53 & $\mathrm{~F}$ & 0 & 17 & 18 & 48 \\
\hline 7 & 51 & $\mathrm{~F}$ & 3 & 13 & 3 & ND \\
\hline 8 & 21 & $\mathrm{~F}$ & 2 & 40 & 7 & ND \\
\hline 9 & 16 & $\mathrm{~F}$ & 3 & 23.5 & 18 & ND \\
\hline 10 & 26 & $\mathrm{~F}$ & 5 & 32 & 44 & ND \\
\hline \multicolumn{7}{|c|}{14709 mutant mtDNA } \\
\hline 11 & 54 & $\mathrm{~F}$ & 7 & 12 & 3 & ND \\
\hline
\end{tabular}

F, female; M, male; ND, not determined.

*Level of heteroplasmy was also quantified in oesophageal, duodenal and intestinal biopsies: respectively 10,44 and $40 \%$. 
of diabetes or the prognosis of the illness (6). For these two reasons, the use of blood samples is not totally suitable for detection of mtDNA mutations in diabetic patients. Buccal mucosa seems to be a good alternative to blood, while results in hair follicles seem to be less reliable. Young onset diabetes mellitus secondary to a respiratory chain defect occurs generally in children in association with multisystemic disorders. Mitochondrial DNA deletions are more frequently observed than point mutations in such patients. When mtDNA is extracted from buccal mucosa and hair follicles, it is not possible to perform 'large fragments' polymerase chain reaction or Southern blot in order to detect mtDNA deletions. So, the analysis of mtDNA extracted from buccal mucosa is primarily recommended in late onset diabetes mellitus.

In conclusion, longitudinal studies in a large number of patients will be necessary to confirm whether searching for mtDNA point mutations in buccal mucosa is able to improve detection of mitochondrial diabetes. Nevertheless, when no mtDNA mutation is found in blood, buccal mucosa and hair follicles should be tested before considering muscle biopsy.

\section{References}

1 Chinnery PF, Zwijnenburg PJG, Walker M, Howell N, Taylor RW, Lightowlers RN et al. Nonrandom tissue distribution of mutant mtDNA. American Journal of Medical Genetics 199985 498-501.

2 Vialettes B, Paquis-Flucklinger V, Pellissier JF, Bendahan D, Narbonne H, Silvestre-Aillaud P et al. Phenotypic expression of diabetes secondary to a T14709C mutation of mitochondrial DNA. Diabetes Care 199720 1731-1737.

3 Kotsimbo N, Bernadette JF, Huizing M, Kapsa R, Lertrit P, Siregar NC et al. Rapid and noninvasive screening of patients with mitochondrial myopathy. Human Mutation 1994 4 132-135.

4 Hart LM, Jansen JJ, Lemkes HHPJ, de Kniff P \& Maassen JA. Heteroplasmy levels of a mitochondrial gene mutation associated with diabetes mellitus decrease in leucocyte DNA upon aging. Human Mutation 19967 193-197.

5 Sue CM, Quigley A, Katsabanis S, Kapsa R, Crimmins DS, Byrne E et al. Detection of MELAS A3243G point mutation in muscle, blood and hair follicles. Journal of the Neurological Sciences 1998 $16136-39$.

6 Asano T, Tsukuda K, Katagiri H, Onishi Y, Sakoda H, Ono H et al. Clinical relevance of heteroplasmic concentration of mitochondrial A3243G mutation in leucocytes. Diabetologia $1999 \mathbf{4 2}$ 1439-1440.

Received 2 May 2001

Accepted 23 May 2001 